\title{
Infections and Systemic Lupus Erythematosus
}

\author{
C. Alejandro Arce-Salinas and Pablo Villaseñor-Ovies \\ Hospital Central Sur de Alta Especialidad, PEMEX \\ Instituto Nacional de Rehabilitación, SSA \\ México City \\ México
}

\section{Introduction}

Notwithstanding that life expectancy in patients with systemic lupus erythematosus (SLE) has improved progressively in the last few decades, the mortality rates remain three times higher as compared with the general population (Uramoto et al, 1998). Reported causes of death vary according to the region of the world, yet there is agreement on the bimodal curve of mortality rate in these patients, with an initial peak occurring early after diagnosis, strongly related with disease activity and infections, and a later escalade associated with cardiovascular disease, accrued damage, and infections too (Rubin et al, 1985). It may be due to its complexity that infectious disease is often considered a grim topic in SLE, but it is undeniable that infections are important contributors of mortality in every stage of the disease.

The range of infections in lupus patients varies widely, from opportunistic infections attributable in some level to immunological dysfunction- to common bacterial and viral infections with typical or atypical presentations. Moreover, patients with lupus exhibit increased proclivity to hospital acquired infections than hospitalized patients with other diagnosis. Some authors have stressed out the association that certain conditions have with the risk of infections in patients with lupus. Some of these include: high disease activity, specific immune dysregulation; drug-induced immune deficiency; and organ failure due to irreversible damage.

On the other hand, several clinical manifestations like fever, lymphadenopathy, unexplained confusion, pulmonary infiltrates, skin and mucosal injuries, coagulation disorders, and others, represent true diagnostic challenges for the clinician who may take them as clues of a lupus flare, or may be compelled to commence a trial of antimicrobial treatment because these may also be the clinical expression of a life-threatening infection, or perhaps, as it often occurs in the field treat both conditions simultaneously. Some evidence suggests that certain infections, particularly of viral nature, might participate in disease initiation, disease flare or worsening of an active lupus condition.

In this chapter we will review the current information regarding infections in patients with SLE, and recommendations to prevent and treat them.

\section{Immune dysfunction and infection in SLE}

Patients with SLE are known to have defects both in the humoral and the cellular branches of the immune system. Some of these defects participate in the inadequacy of immune 
defense against pathogens. The relationship between altered immune function and infections in SLE is exceedingly complex, as infectious agents can interact with the immune system in several ways, and the immune system itself works as an intricate, overlapping and sometimes redundant network of signals and checkpoints under different levels of control. Of course, the defective immune function is not universal and as in other aspects of the disease, its expression is not homogenous among lupus patients and hence susceptibility to different pathogens is reasonably variable. The potential role of macrophage and polymorphonuclear defects, reduced numbers and dysfunction of T-cells and B-cells, defects in the production of immunoglobulin and altered function of the reticuloendothelial system are all considered to take part in the altered immune response against pathogens that is present in a proportion of patients with SLE (Sebastiani \& Galeazzi, 2009; Iliopoulos \& Tsokos, 1996).

All this is further complicated by the almost obligated use of immunosuppressant drugs to control disease activity. Nevertheless, the young readers will be surprised to know that 60 years ago, lupus was not treated with steroids or immunossuppresants and despite that, infection was still one of the major causes of death in lupus patients. (Klemperer, et al 1941)

\subsection{Defects in the complement system}

The complement system plays a crucial role in host defense against pathogens and the increased infection rates observed in SLE patients have been attributed in part to defects of the complement system that are in turn, frequent in SLE. Genetic deficiencies of early components of the classical pathway are major risk factors for the development of lupus, particularly $\mathrm{C} 1 \mathrm{q}$ deficiency. Since $\mathrm{C} 1 \mathrm{q}$ plays an important role in complement activation through the recognition and clearance of apoptotic material, antibodies and structural proteins on bacteria and viruses, it is not surprising that a deficient state would increase susceptibility to infection. Also the consumption of complement components by immune complexes is also considered to limit the amount of complement available to be used against invading pathogens. Reduction of other components of the complement system comes with various risk degrees of specific infections, i.e. C3: encapsulated bacteria, C5-C9: Neisserial infections. (Pickering et al, 2000; Figueroa \& Densen, 1991)

\subsection{Mannose-Binding Lectin (MBL) and Infections in SLE}

The lectin pathway of complement activation is also implicated in the pathogenesis of lupus and most likely in the increased propensity to infections in this disease, as well. MBL is a serum protein that serves as a recognition particle in the lectin pathway of complement activation. Additionally, MLB may directly opsonise pathogenic microorganisms and activate phagocytes. Several studies have demonstrated that variant alleles of MBL are associated with an increased risk for the development of SLE. Furthermore, among patients with SLE, those homozygous for MBL allelic variants had an increased risk of serious infections in comparison with patients heterozygous of homozygous for the normal allele (M.Y. Mok et al, 2007a). Other studies have failed to demonstrate a connection between functional MBL activity and the occurrence of infections (Bultink et al, 2006). This discrepancy between the genotypic and phenotypic data could be explained by the fact that functional activity of MBL is not only determined by mutations on its encoding gene. Also, the immune system has redundancies and in most cases, increased susceptibility to infection with MBL deficiency arises when other factors are inducing immune dysfunction (i.e. 
immunosuppressive drugs). In fact, low levels of MBL are associated with poorer outcomes in severe infections, even in otherwise immunocompetent individuals. In synthesis, a proportion of patients with lupus appear to have increased frequency of infections related to allele variants of MBL; such infections are for the most part from encapsulated bacteria, and most likely owing to defective opsonization (Monticielo et al, 2008; Super et al. 1989).

\subsection{Cellular immune defects}

The diminished phagocytic activity observed in monocytes from patients with lupus, may be due to a decrease in the production of TNF- $\alpha$, deficit in the generation of superoxide, or by the presence of specific autoantibodies against receptor Fc $\gamma$. These autoantibodies may have a wider effect over the immune system because these receptors also exist on the surface of B-cells, natural killer cells, and some T-cells (Boros et al, 1993; Yu et al, 1989). Defective phagocytosis has also long been noticed in polymorphonuclear leukocytes in patients with lupus. Although the presence of antibodies against neutrophil cytoplasmic components, some of which are directly involved in pathogen fighting (i.e. lactoferrin, elastase and lysozyme), has been reported in SLE, its clinical significance is still obscure. Their presence has no influence over total number of neutrophils and their precise contribution to the increased susceptibility to infections in SLE, remains to be determined (Lee et al, 1992; Schnabel et al, 1995).

T-cell lymphopenia is the most common quantitative disorder observed in the blood of patients with lupus. Lymphopenia correlates with disease flares and responds to immunosuppressive treatment. It is generally considered to be a major contributor in the increased propensity to infections. T-cells also exhibit important functional deficits. Impaired T-cell cytolytic activity is largely attributable to a decreased production of interleukin- 2 and $\gamma$-interferon and is more prominent within the CD8+ T-cell population. On top of the reduced delayed hypersensitivity skin response that happens in patients with SLE. A group of studies pointed out that an important proportion of patients with SLE have altered in vitro immune responses to alloantigens and recall antigens, and that such dysfunction correlates with higher disease activity. (Yu et al, 1989; Gumma et al, 1994).

In general, B-cell functions seem unaltered in SLE. Antibody production and immunization are preserved in the majority of cases, but some B-cell and immunoglobulin alterations have been described. Scattered reports of transient or permanent hypogammaglobulinemia with an increased risk of infections were informed prior to the use of anti-CD20 therapies. Alternatively, many patients with SLE display a prominent polyclonal B-cell activation and hypergammaglobulinemia (Yong et al, 2008, Karim 2006; Battafarano et al 1998).

Transient or permanent spleen dysfunction is associated with diverse autoimmune diseases including SLE. In SLE, functional asplenia, defined as failure of splenic uptake of a radiolabeled colloid is present in approximately $5 \%$ and seems to correlate with disease activity. Asplenia increases vulnerability to pneumoccocal and Salmonella infections (Fishman \& Isenbert, 1997). Table 1 summarizes factors predisposing SLE patients to infections.

\section{Epidemiology of infections in systemic lupus erythematosus}

Although infections in SLE remain as an important clinical concern that should have a prominent place in the research agenda in lupus, there is a notorious absence of high-quality studies addressing this phenomenon. The majority of studies involve hospitalized patients, a population that certainly has a selection bias and limits their external validity; also, we 


\section{Cellular immunity}

T-cell lymphopenia

Impaired T-cell cytotoxic activity

Altered recall of antigens

Diminution of NK-cell function and number

\section{Humoral immunity}

Antibodies against $\mathrm{F} c \gamma$ receptor

Antibodies against neutrophil cytoplasmic components

Hypogammaglobulinemia

\section{Phagocytic deficiency}

Mononuclear cell defective phagocytosis

Deficit in superoxide generation

\section{Cytokine defects and other immune anomalies}

Mannose-binding lectin allelic variants

Hypocomplementemia

Decrease in the production of TNF- $\alpha$

Decrease of IL-2 production

Other cytokine imbalance (IL-10, $\gamma$-interferon, IL-1)

\section{Disease related}

Disease activity and/or glucocorticoid use

Transient or permanent spleen dysfunction

Accrued damage (irreversible damage, i.e. ESRD, lung fibrosis, etc.)

\section{Treatment related}

Immunosuppressive drugs

Glucocorticoids

Immune targeted biologic agents

\section{Table 1. Summary of factors related to infection propensity in SLE}

found a great number of patient series and case reports of outstanding features but only a few prospective cohorts in most of which the outpatient setting had been neglected.

Morbidity of lupus patients varies with the chronological stage of the disease. In subjects with short disease duration, the most important causes of hospitalization and medical attention are related to disease activity and common bacterial or viral infections and few opportunistic infections. With the improved survival rates and longer disease duration, other morbid conditions are commonly identified in longstanding disease; the most regularly described are accelerated atherosclerosis and cardiovascular disease, osteoporosis, osteonecrosis, cognitive dysfunction, chronic fatigue, fibromyalgia, malignancies and the coexistence with other chronic illnesses such as diabetes mellitus and systemic hypertension. However, infectious disease is still one of the most important causes of hospitalizations and death in this group.

In a large cohort of patients with SLE followed in several European countries, the annual incidence of infection was $27 \%$ during the first 5 years. A follow-up report indicates that 
infections continued to be the cause of one fifth of all hospitalizations in the second half of the 10 year follow-up, with a notorious reduction in the diagnosis of sepsis in this later period (Cervera et al, 2003). Other authors have reported on the burden of infectious disease in SLE: close to $15 \%$ of patients with lupus are hospitalized for major infections every year; the risk of major infection is $60 \%$ higher in SLE as compared with other chronic diseases, and many of them are treated in the ICU. A bacterial etiology is detected in the majority of cases and lower respiratory tract is the most important site of infection. Mexican researchers performed a study to determine the incidence of infections in their group; among the ambulatory patients, $57 \%$ of hospitalizations were due to infection of any kind, and although diagnostic confirmation was achieved only in one third of their cohort, all patients with suspicion of infection, received complete antibiotic courses. They found $12.5 \%$ of nosocomial infections in non-infected subjects admitted for other reasons (Navarro-Zarza et al, 2010). Furthermore, Al-Arfaj in Arabia found, in patients followed by almost 30 years with a remarkable long-term survival, that $50 \%$ of deceases were related to severe bacterial sepsis, mainly in subjects with renal failure (Al-Arfaj \& Khalil, 2009). Other groups in different regions of the world report similar rates of infections in SLE, emphasizing that these complications remain as a significant problem both in the outpatient care and in the hospital setting.

Infections are also a prominent cause of death among lupus patients. On the early 1980's, a multicenter evaluation in more than 1,000 lupus patients was reported, revealing that one third of registered deaths were caused by infections and another third because of disease activity. Other authors, in different regions of the world, have assessed the issue of mortality due to infections, and with different methodological approaches, mortality rate associated to this cause is reported from 14 to $50 \%$ of all deaths (Cervera et al, 2003; Zandman-Goddard \& Shoenfeld, 2003; Gladman et al, 2002).Table 2 depicts impact of infections in general mortality of SLE patients.

The nature of most infections in lupus patients either in the ambulatory or nosocomial settings is mainly of bacterial origin, being lower respiratory and urinary tract infections the most frequently registered, with less cases of sepsis of unknown cause, soft tissue \& skin and other common bacterial infections (Gladman et al, 2002; Iliopoulos \& Tsokos, 1996). Nevertheless, it should be underlined that non-complicated infections occurring on ambulatory settings are not usually recorded, and it is possible these may be underestimations of the true burden they give. In a prospective study of an outpatient clinic, an incidence of $32 \%$ of infections along 2 years of follow-up was observed. Urinary tract infections (UTI) due to Escherichia coli, skin infections produced by Staphylococcus aureus, and simultaneous infections of different sites were the most frequently registered; the majority were treated on ambulatory basis with good results (Zonana-Nacach et al, 2001).

Nosocomial infections are a noteworthy issue to address in this scenery. Some investigators reported that more than a half of infections diagnosed in SLE patients are of a nosocomial source, mostly upper and lower respiratory and bloodstream infections; patients with organ dysfunctions and with high-steroid dose are more susceptible to acquire nosocomial infections. The most important information in this regard comes from Navarro-Zarza's cohort, indicating an incidence rate of $12.5 \%$ among patients who had neither symptoms nor clinical suspicion of infection at admission, and afterward develop nosocomial infections; higher disease activity score measured by the Mex-SLEDAI (Guzmán et al, 1992), high damage scores (SLICC/ACR), immunosuppressive treatment and length of hospital stay were all risk factors for the development of nosocomial infection (Navarro-Zarza et al, 2010). 
Consequently, lupus patients admitted for hospital care are at higher risk of infection and any action to lower their incidence, by every member of the healthcare team should be implemented with emphasis.

\begin{tabular}{|c|c|c|c|c|}
\hline Author, year/Site & $\begin{array}{l}\text { \# of patients } \\
\text { followed by time }\end{array}$ & $\begin{array}{l}\text { \# of } \\
\text { deaths }\end{array}$ & Survival & $\begin{array}{l}\% \text { of deceases } \\
\text { due to } \\
\text { infections }\end{array}$ \\
\hline C.C.Mok, 2000/China & 186 by $7 y$ & 9 & $93 \%-5 y$ & $75 \%$ \\
\hline $\begin{array}{l}\text { Kasitanon, } 2002 \\
\text { /Thailand }\end{array}$ & 349 by $14 \mathrm{y}$ & 52 & $84 \%-5 y ; 75 \%-10 y$ & $35 \%$ \\
\hline Cervera, 2003/Europe & 1,000 by $10 y$ & 68 & $97 \%-5 y ; 92 \%-10 y$ & $25 \%$ \\
\hline $\begin{array}{l}\text { Pons-Estel 2004/Latin } \\
\text { America }\end{array}$ & 1,214 by $3 y$ & 34 & ND & $58 \%$ \\
\hline $\begin{array}{l}\text { Bernatsky, 2006/North- } \\
\text { America\$ }\end{array}$ & 9,547 by $30 \mathrm{y}$ & 1,255 & ND & $5 \%$ \\
\hline $\begin{array}{l}\text { Wadee, 2007/South } \\
\text { Africa }\end{array}$ & 226 by $15 y$ & 55 & $72 \%-5 y ; 58 \%-10 y$ & $44 \%$ \\
\hline Nossent, 2007/Europe & 2,500 by $5 y$ & 91 & ND & $57 \%$ \\
\hline $\begin{array}{l}\text { Al-Arfaj, 2009/ Saudi } \\
\text { Arabia }\end{array}$ & 624 by $30 y$ & 25 & $98 \%-5 y ; 97 \%-10 y$ & $48 \%$ \\
\hline Goldblatt, 2009/UK & 104 (of 407) by $29 \mathrm{y}$ & 67 & ND & $25 \%$ \\
\hline
\end{tabular}

ฯ Only reports results of 104 patients hospitalized form a cohort of 470

\$Study in 23 Centers of US, Canada and UK, only 1 in Sweden and 1 in Iceland

Table 2. Percentage of deaths due to infections in some studies around the world.

Infectious diseases in SLE patients admitted to the ICU require an additional comment. Most admissions to the ICU in lupus patients are related to infection, and a considerable mortality is usually observed $(45-86 \%)$; the most often reported predictive markers are: higher APACHE-II scores, length of stay in the ICU, and inadequate initial selection of antibiotics. It has been shown that not infected patients with SLE admitted to the ICU with lupus flares, exhibit high mortality rates (75-95\%), and nosocomial acquired infections are a relevant complication in most cases. These reports, as well as others (Alzeer et al, 2004), highlight the importance of pneumonia and bacterial sepsis of unknown origin as the most frequent reason for admission to ICU, and their relationship with poor outcomes.

\subsection{Usual bacterial infections}

Common microorganisms underlie the majority of infections among lupus patients. Pneumonia and respiratory tract infections are the most recognized (Petri, 2008). Some immune defects increase susceptibility to certain bacteria, but no comparative studies have made clear the possible connection that such defects may have with specific infections. Continuing on the subject of common infections, S. aureus and Streptococcus pyogenes persist as the most frequent etiology of respiratory infections. However, as mentioned, information related to respiratory infection in the outpatient setting is scarce, and not surprisingly pathogens differ in the hospitalized subject; gram-negative bacteria appear as key pathogens 
in respiratory infections in these circumstances, being Klebsiella sp, Pseudomonas aeruginosa, and E. coli mainly involved. Streptococcus pneumoniae has been reported as a cause of septicemia; interestingly, lower rates of pneumococcal septicemia have been seen after the implementation of routine vaccination.

Bladder dysfunction seems to be more prevalent among women with SLE; in an outpatient cohort, near to $10 \%$ suffered of recurrent infection and depict abnormal voiding function tests, with small bladder capacity, reduced bladder sensation, residual urine and abnormal urinary flows. These data were alike to those reported by others, and also shows a possible association of these abnormalities and disease activity. Urinary tract infections are very common among women with SLE, and the functional derangements previously mentioned are found often, particularly in cases of recurrent infections. E coli and Streptococcus agalactiae were the most prevalent recovered microorganisms (Durán-Barragán et al, 2008).

Infections due to Salmonella species are important cause of bacteremia after ingestion of contaminated food; inasmuch as underdeveloped countries have more risk conditions to this infection, it has been reported more frequently in these regions of the world. Lupus patients' conditions are prone to develop primary bacteremia, extra-intestinal collections, osteomyelitis, septic arthritis, infective endocarditis, bloodstream and endovascular infections, even in absence of gastrointestinal symptoms. Infections of different Salmonella serogroups are also related to high mortality, as it has been shown after bacteremia episodes. Risk factors for mortality due to Salmonella infection are re-infection, older age and concomitant infection with other microorganisms; a high index of suspicion is vital, insofar as salmonellosis and SLE have similarities in clinical manifestations like fever, rash, pleurisy, abdominal complaints and synovitis. Table 3 describes the main pathogens observed in prospective or relevant studies in different regions of the world.

\subsection{Infections due to Mycobacteria}

Infections as a consequence of Mycobacterium species are of two groups: infections due to $M$ tuberculosis, that trend to occur early in the course of lupus, related to disease activity and treatment, and usually resulting mainly from reactivation of latent infection or to reinfection; and infections to non-tuberculous Mycobacterium (NTM), presenting later in the course of disease and predominantly as a new infection, including $M$. avium complex, $M$. chelonae, M. haemophilum or M. fortitum (Cuchacovich \& Gedalia, 2009). Mok et al (M.Y. Mok et al, 2007b) describes 11 cases of NTM infections localized in skin and soft tissues, in patients with long disease duration and long cumulative prednisone dose. In transplant patients, SLE remains as a risk factor for tuberculosis with a substantial increase of mortality among patients with this infection.

Mycobacterium tuberculosis infections represent a great problem to many countries around the world. The HIV pandemic and use of biologic immune-regulator agents for other rheumatic conditions are related to rise of tuberculosis (TB) in regions where TB was believed near to ending (Mathers \& Loncar, 2006). In point of fact, since the first use of highsteroid doses in rheumatic diseases, an increase of TB infections was noticed, as well as reactivation of previously treated TB once steroids were newly administered (Yun et al, 2002); besides, occurrence of TB is closely and directly interrelated to the mean daily doses or cumulative steroid-dose. In lupus patients, TB is a major contributor of morbidity and mortality. There seems to be a higher risk for this infection and clinical illness in these patients is often extra-pulmonary (miliary) where hematogenous dissemination is usually 


\begin{tabular}{|c|c|c|c|c|}
\hline Author, year/Site & $\begin{array}{l}\text { \# patients } \\
\text { observed }\end{array}$ & $\begin{array}{l}\text { \# of } \\
\text { infections }\end{array}$ & $\begin{array}{l}\text { Main pathogens } \\
\text { (Percentage of total) }\end{array}$ & Characteristics \\
\hline $\begin{array}{l}\text { Oh, } \\
\text { 1993/Singapore }\end{array}$ & 28 & 38 & $\begin{array}{l}\text { S. aureus }(21 \%) \\
\text { P. aeruginosa }(11 \%) \\
\text { Klebsiella sp. }(11 \%) \\
\text { E. coli }(7 \%) \\
\text { M. tuberculosis }(7 \%)\end{array}$ & $\begin{array}{l}\text { Hospitalized patients } \\
\text { followed by } 8 \text { months }\end{array}$ \\
\hline $\begin{array}{l}\text { Zonana-Nacach, } \\
\text { 2001/Mexico }\end{array}$ & 200 & 65 & $\begin{array}{l}\text { E. coli }(25 \%) \\
\text { S. aureus }(8 \%) \\
\text { Candida sp. }(6 \%) \\
\text { M. tuberculosis }(2 \%) \\
\text { Salmonella sp. }(2 \%)\end{array}$ & $\begin{array}{l}\text { Outpatient only. Two } \\
\text { years of observation }\end{array}$ \\
\hline Leone, 2007/Brazil & 71 & 48 & $\begin{array}{l}\text { S aureus }(50 \%) \\
\text { P. aeruginosa }(17 \%) \\
\text { Candida sp. }(17 \%) \\
\text { Aspergillus sp. }(17 \%)\end{array}$ & $\begin{array}{l}\text { Juvenile SLE, } 18 \\
\text { deaths. }\end{array}$ \\
\hline $\begin{array}{l}\text { Ramírez-Gómez, } \\
\text { 2007/Colombia }\end{array}$ & ND & 123 & $\begin{array}{l}\text { E. coli }(22 \%) \\
\text { Staphylococcus sp. }(15 \%) \\
\text { Klebsiella sp. }(9 \%) \\
\text { Candida sp. }(9 \%) \\
\text { P. aeruginosa }(4 \%)\end{array}$ & $\begin{array}{l}\text { All nosocomial } \\
\text { acquired. High } \\
\text { disease activity } \\
(\text { SLEDAI }>11) \text {. Three } \\
\text { years of observations }\end{array}$ \\
\hline $\begin{array}{l}\text { Ruiz-Irastorza, } \\
\text { 2009/Spain }\end{array}$ & 249 & 88 & $\begin{array}{l}\text { E. coli } 16 \% \\
\text { S. aureus } 14 \% \\
\text { M. tuberculosis } 12 \% \\
\text { S. pneumoniae } 9 \% \\
\text { Candida sp. } 7 \%\end{array}$ & $\begin{array}{l}\text { Major infections } \\
\text { (organ dysfunction, } \\
\text { hospitalized) }\end{array}$ \\
\hline $\begin{array}{l}\text { Navarro-Zarza, } \\
\text { 2010/Mexico }\end{array}$ & 473 & $\begin{array}{l}268 \\
\text { (confirmed 96) }\end{array}$ & $\begin{array}{l}\text { E. coli }(48 \%) \\
\text { Candida sp. }(21 \%) \\
\text { Staphylococcus sp. }(15 \%) \\
\text { Streptococcus sp. }(12 \%) \\
\text { M. tuberculosis } 4.5 \%\end{array}$ & $\begin{array}{l}\text { Community acquired } \\
\text { infections seen along } \\
5 \text { years }\end{array}$ \\
\hline
\end{tabular}

Table 3. Pathogens frequency in some prospective studies around the world

the mechanism involved (Hou et al, 2008). Extra-pulmonary tuberculosis presents a wide range of symptoms, which may confound with other diseases, or with disease activity; symptoms like arthritis, lymphadenopathy, lung nodules, pulmonary infiltrates, pleural effusion, weight loss and renal abnormalities offer this challenge, so, workup to identify mycobacteria is imperative. Moreover, in a review of patients with central nervous system involvement, $M$. tuberculosis represents a frequent cause of meningitis that requires prompt recognition and treatment, since it is linked to high mortality and severe functional sequels (Yang et al, 2007). Burden of TB in SLE is higher in countries were TB is endemic; for instance, incidence may vary from less than $1 \%$ in industrialized countries to $11.6 \%$ in India (Falagas et al, 2007) with a 6-fold risk of TB among SLE patients in Spain to 15-fold in Hong 
Kong and 60-fold in India. In a study of overall infections among lupus patients, TB was the most frequently diagnosed and extra-pulmonary localization was present in one quarter of patients. In addition, TB was found during the first year of lupus diagnosis in $60 \%$ and $80 \%$ in the first 24 months, mainly linked to a major organ dysfunction or aggressive treatment (Shyam \& Malaviya, 1996).

Diagnosis of TB and NTM infections in lupus patient represents a challenge for clinicians due to the overlap of symptoms and laboratorial abnormalities produced by both conditions; however, search for mycobacteria in tissues and corporal fluids, cultures and serological test, even with genetic material amplification, as well as ADA assay, tuberculin test, and $\gamma$-interferon assays seem to be equally accurate than in non-SLE patients. It's fair to mention that some variations have been reported in the diagnostic yield of some of these tests that require further assessment. (Prabu et al, 2010). Treatment of TB and NTM infections should be provided accordingly to WHO guidelines taking into account the local antimicrobial resistance rates. The question of isoniazid prophylaxis in these patients will be discussed later.

\subsection{Opportunistic infections}

Immunological abnormalities in lupus patients related to dysregulation of both, humoral and cellular responses have been extensively documented. Besides, drugs used to treat SLE exert diverse degrees of immune system turndown that deepen the problem of immune fighting against pathogens (I. Kang et al, 2003). Opportunistic infections, considered as those caused by non-pathogenic microorganisms not often seen in individuals with normal immune conditions, which lead to clinically significant consequences in immunocompromised subjects, are frequently reported in SLE patients. Furthermore, its difficult to know the real load that this type of infections represent in SLE since frequency rates are yet to be determined for most of them. On the other hand, case-reports and small case series are abundant on this topic. Nonetheless, in all cohorts describing lupus patients with infectious diseases there are cases with opportunistic infections either of bacterial, fungal, protozoan or viral origin; lot of cases had overlapping manifestations between disease activity and infection leading to treatment delay and poor outcomes.

\subsubsection{Opportunistic infections of viral origin}

Viral infections in SLE have been suspected to play a pathogenic role on development, trigger and flare of disease. Some authors have demonstrated activation of immune system and antibodies production during acute viral infections, as we mentioned before. On the other hand, besides its suggested pathogenic role in autoimmune diseases, acute viral infections are frequently reported as partners of disease flares or at disease presentation, confusing and favoring misinterpretation of clinical signs and deferral of adequate treatment (Ramos-Casals et al, 2008).

Herpes zoster (HZ) is the symptomatic reactivation of the varicella-zoster virus (VZV), an infection frequently acquired at childhood; virus prevails in a latent stage in the dorsal root ganglia for long periods of time; more than $90 \%$ of adults have serologic evidence of a previous VZV infection. Control of latent virus at ganglia is exerted by humoral and cellular mechanisms; its reactivation requires a change of immune system balance. The incidence rate of $\mathrm{HZ}$ is $32.5 / 1,000$ patients-year, from a group of prospectively followed lupus patients, which is at least 2-3 fold greater than the general population (T.Y. Kang et al, 2005). 
In a national survey in an Asian country, SLE was the most important risk factor to develop $\mathrm{HZ}$ at population level. Major complications of $\mathrm{HZ}$ are visceral dissemination with CNS, lung and liver involvement. Use of immunosuppressant drugs is the most relevant risk factor for complicated HZ; presence of lupus nephritis and disease activity has been also mentioned. Particular genetic abnormalities have not been found in association with HZ infection. Lupus patients have more severe forms of infection, with disseminated disease in $11-20 \%$ of cases, higher number of cases with ocular involvement, and post-herpetic neuralgia (Borba et al, 2010). Treatment of this condition should be carried out accordingly to current guidelines. A live attenuated varicella virus vaccine has not been tested in SLE patients and is not recommended in patients using any type of immunosuppressant.

Cytomegalovirus (CMV) infection is a life-threatening that endangers organ function in immunocompromised host, either as primary infection or as a reactivation of latent CMV. Although in other conditions associated with immune dysfunction reports of visceral, eye, CNS involvement and graft rejection due to this viral disease are ubiquitous. CMV infection is also relevant in pregnant women since it is a frequent cause of newborn morbidity and mortality. Seroprevalence of CMV antibodies in healthy population have been found to range from 50 to $80 \%$ in US. In lupus patients, clinical infections often come from reactivation of latent virus when aggressive immunosuppressive therapy is installed. Clinical pictures are wide: pneumonia and alveolar hemorrhage, skin ulcers, proteinuria and renal failure, thrombocytopenia, pancytopenia, hepatitis, vasculitis, retinitis and encephalitis. It may be underseeked and hence underdiagnosed but only few cases with any of these complications are reported in SLE (Ramos-Casals et al, 2008). Diagnosis of CMV is made with serology, although a note of caution should be taken: false positive reactions are not infrequent, presumably because of secondary production by auto-reactive B-cells. Other tools for diagnosis are DNA amplification of viral material as well as the characteristic cellular changes seen in biopsies. Antiviral agents to treat this disease should be initiated once a reasonable suspicion is present because it is linked to a considerable mortality and irreversible organ dysfunction, and in the clinical arena it is often difficult to wait for an unquestionable diagnosis; ganciclovir and its pro-drug valganciclovir, foscarnet and cidofovir are currently used in this setting, with the necessity of a tight monitoring due to its potential serious adverse effects. Up till now, attempts to develop an effective vaccine to prevent CMV infection by several researches around the world, either in the general population or in some special groups, have not been successfully (Gandhi \& Khanna, 2004). Epstein-Barr virus (EBV) infection importance resides in its temporal relationship with lupus initiation; moreover, EBV infection is relevant because of the immunological abnormalities found during and after exposure to this virus (Barzilai et al, 2007), the defective control of latent infection seen in lupus patients (I. Kang, 2004) and the higher prevalence of serum antibodies against EBV observed in subjects with SLE as compared with other patient groups. In Ramos-Casals' review, only a few cases with EBV infection were obtained, and no patient had organ-specific involvement; such cases had lymphadenopathy, fever and rash often considered manifestation of disease activity may well represent mild infections with EBV. We found very interesting a report of lymphoma with EBV infection in a patient receiving azathioprine that regressed after withdrawal of immunosuppressive therapy (Evans et al, 2008). No specific treatment for this condition has been described.

Human papillomavirus infection has demonstrated to be cause of genital, rectal and laryngeal cancer. Uterine cancer is the most important malignancy of those linked to HPV infection, due to its high incidence in third world countries. In 2010 it remains a public 
health problem in poor countries, in spite of the many healthcare programs of prevention, early detection and treatment of pre-malignant lesions (Clifford et al, 2005). Lupus women have higher prevalence of HPV infection compared with a control group, as well as highrisk variants of the virus (Klumb et al, 2010). Furthermore, there might be more risk of squamous intraepithelial lesion because of a higher prevalence of identified factors of disease progression, such as persistence of high-risk HPV variants and the use of cyclophosphamide. Progression to neoplasia is probably more frequent among SLE patients also. Therefore, SLE women require close follow-ups, particularly in women with sexual activity and/or presence of the virus in the cervix. Treatment of those with high-risk variants and adherence to management guidelines of squamous epithelial lesions and cervical intraepithelial neoplasia should be warranted. No evidence of impact of recently applied programs of vaccination in these patients can be made due to current short length of follow-up.

Parvovirus infection has also been associated with pure red-cell aplasia, hydrops fetalis and acute and chronic arthropathy; other clinical manifestations such as rash, fever, lymphadenopathy, and blood cell abnormalities may also puzzle the clinician into a misdiagnosis of SLE. Careful assessment and follow-up will differentiate between both conditions (Severin et al, 2003). Diagnosis of infection is made by serology or viral DNA amplification, no treatment for this condition has been described as a great majority of cases have self-limited disease. No methods of prevention are available.

Hepatitis C-virus (HCV) infection has a worldwide distribution and is endemic in some regions. It is the most common cause of chronic liver disease and the global prevalence has been estimated in $2 \%$, more than 120 million people around the world might be currently infected (Shepard et al, 2005). Coexistence of SLE and HCV infection is therefore not an unusual treat. HCV infection is the viral illness with the most described muscle skeletal and autoimmune manifestations resembling rheumatic conditions, mostly acute and chronic polyarthritis, vasculitis, glomerulonephritis, neuropathy, thrombocytopenia, cryoglobulinemia and other laboratory anomalies, including positive antinuclear antibodies, low complement levels and anti-DNA antibodies, which are indistinguishable of the idiopathic diseases. In a comparison of lupus patients with and without HCV infection, some authors found a large prevalence of infection among SLE patients belonging from the same population, with lower frequency of cutaneous features and anti-dsDNA antibodies, as well as a higher prevalence of cryoglobulinemia, hypocomplementemia and liver test abnormalities (Ramos-Casals et al, 2000). HCV infection may mimic not only SLE, but Sjögren syndrome, polyarteritis nodosa and rheumatoid arthritis also (Sharlala \& Adebajo, 2008; Becker \& Winthrop, 2010) and may play a pathogenic role in autoimmune thyroiditis and Behçet's disease. On the other hand, a2interferon therapy used for the treatment of chronic HCV may induce SLE which may or may not regress after withdrawal. Also, clinicians should bear in mind that SLE has been described as a remarkable cause of false positive serology for $\mathrm{HCV}$.

Other viral infections in lupus patients such as mumps, measles, herpesvirus-6, or herpes simplex virus are seldom reported and seem not to have relevance interactions of these viral agents and SLE (Ramos-Casals et al, 2008).

\subsection{Rare bacterial infections}

Listeria monocytogenes is a ubiquitous pathogen that causes disease in animals and humans. Outbreaks of listeriosis in relation to contaminated food have been reported in immunocompetent hosts. In immune deficient patients it is frequently a fatal infection with 
sepsis and CNS involvement. In an analysis of 38 lupus patients with CNS infections, Yang et al (Yang et al, 2007) found tuberculosis in a half, L. monocytogenes in 3, other gram-positive and gram-negative bacteria in 3 cases, Cryptococcus neoformans in 12 and Aspergillus fumigatus in 1; high steroid dose and low albumin were related to unfavorable outcome. In other series, listeriosis mainly manifested as meningitis in SLE patients with remarkable high mortality (Kraus et al, 1994). Antibiotic regimen in acute bacterial meningitis in lupus patients should include an agent with anti-listerial activity.

The Nocardia genus includes a group of soil gram-positive saprophyte aerobic actinobacteria. Nocardia causes human infections that are difficult to diagnose because of unspecific clinical or histological manifestations. There are reports of several lupus cases complicated with Nocardia infections; lungs were the most common site of involvement $(81 \%)$, followed by the central nervous system (C.C. Mok et al, 1997). A high degree of suspicion to identify this infection is required.

\subsection{Opportunistic Infections of fungal origin}

Fungal infectious disease is more often recognized in hospitalized patients owing to the more extensive use of broad-spectrum antibiotics. In lupus patients, the most common fungal infections are, as in other chronic immune deficient states, those produced by Candida species, which may affect pharynx, esophagus, and the urinary tract or may present themselves as a primary bloodstream infection. A relationship with high steroid doses and intense immunosuppression is suggested by many. Pneumocystis jiroveci (formerly carinii) has been acknowledged as a cause of severe pulmonary involvement in chronic disease with deficient immune function. There are several reports of $P$. jiroveci pneumonia in patients with rheumatic disorders after intense immunosuppression. It has been suggested that SLE patients have more dramatic disease behavior and higher mortality rates, but this remains speculative. Patients receiving high dose steroids ( $>40 \mathrm{mg}$ of prednisone or equivalent, for more than three months) or a combination of immunosuppressants, and with lung involvement of SLE (i.e. autoimmune alveolitis) may be considered for a prophylactic trial of antimicrobials. (Vernovsky \& Dellaripa, 2000).

C. neoformans is ubiquitous encapsulated yeast that causes severe neurological infections and other disseminated diseases in immunocompromised hosts. In several fatal cases of lupus patients with meningeal infection, $C$. neoformans has been seen as a causative agent. Moreover, in a group of lupus patients with invasive fungal infections, C. neoformans represented almost $70 \%$ of cases, with both meningeal and disseminated disease. Prompt initiation of active antifungal treatment is mandatory in accordance to the elevated mortality registered in these cases. Other fungal agents such as Aspergillus fumigatus and mucor species have been reported and recently reviewed (Arce-Salinas et al, 2010).

\subsection{Parasitic infections in SLE}

Parasitic diseases remain as a major cause of morbidity and mortality in the tropical areas and in the underdeveloped world. Malaria persists in at least 109 countries and affects 300 million people around the world. No relevant association with clinical manifestations of lupus or with its treatment has been reported. Also, no particular clinical picture of malaria in this population has been mentioned. Nevertheless, relationship of the parasite and lupus resides in the production of antibodies cross-reacting against Plasmodium parasites found in some patients (Zanini et al, 2009); and the fact that anti-ribosomal $\mathrm{P}$ protein antibodies produced by lupus patients cross-react with the ribosomal 
phosphoprotein P0 of Plasmodium falciparum and exert a potent inhibition of the parasite growth in vitro (Singh et al, 2001), the clinical significance of this interesting observation remains elusive. On the other hand, IgM anti-phospholipid antibodies have been recognized in patients with active malaria infection (Jakobsen et al, 1993), mainly against phosphatidylinositol, phsophatidylcholine and cardiolipin; high titers correlated with infection severity and poor outcome.

Exposure to Toxoplasma gondii accordingly to seroprevalence studies is widely distributed; its importance increases in pregnant women (increased risk of fetal neurological damage), and in immune deficient hosts, in whom encephalitis, retinal damage, pneumonitis and other severe manifestations may occur. In lupus patients there are a few case-reports of patient with neurological or ocular involvement, as well lymphadenopathy and fever, again mimicking disease activity (Seta et al, 2002).

Strongyloides stercoralis, a soil worm that infects humans in tropical areas should be in mind of every clinician caring for SLE patients. S. stercolaris clinical infection has a prevalence that ranges from 0.1 to $11 \%$ depending the way in which it is sought (serum antibodies, stool ova or other methods). Generally its infection produces a few intestinal symptoms and its relevance, besides its infectivity, is a consequence of the autoinfection cycle that permits blood larvae migration. Without effective cellular immune control disseminated disease develops. Some lupus cases complicated with overwhelming strongyloidosis have been described; some authors suggest that stool examination looking for parasite's ova and preventive treatment could be recommended for patients at risk who will receive intense treatment for SLE. Albendazol or ivermectin have been used in chronic and disseminated infection, and the few reports describing this condition are related with poor outcome (Caramaschi et al, 2010).

\section{Approach to fever in SLE}

Fever in lupus patients represents a challenge for the clinician, who must face up with finding ways to determine the most likely origin between a lupus flare and active infection, bearing in mind that often both require prompt treatment. In an old report Harvey, said fever was a manifestation of disease activity in at least $86 \%$ of their patients, later Daniel Wallace draw attention to the decline of fever as a symptom of disease activity in reports of the 1980's and early 1990's; he thought that such decrease was related with frequent and earlier use of NSAIDs and glucocorticoids. Moreover, febrile lupus patients are habitually seen in both the outpatient clinic and the hospital wards. The workup requires an intelligent and sequential approach to recognize the true nature of fever. Lupus patients with fever may show certain patterns of clinical behavior that correspond, more or less, to clinical scenarios that entail different actions. Firstly, a patient recently diagnosed, without treatment and with active lupus disease including fever among other manifestations; in these cases, treatment beginning, particularly with steroids, produces a rapid disappearance of fever; when fever persists, the search of an infectious source is mandatory with appropriate cultures. Secondly, patients with fever who have inactive disease or mild disease activity in their last follow-up visits, often in the outpatient situation, and may or may not be receiving low steroid dose, antimalarials or a mild immunosuppressive regimen; in this cases, a thorough clinical assessment and studies in hunt of common bacterial infections followed by currently recommended empirical antibiotic treatment is warranted and associated with resolution of fever. 
In a lupus patient hospitalized because of persistent fever, a meticulous clinical evaluation is critical, followed by the workup study based on its findings and suspected diagnosis; an assessment of disease activity with a validated index is also suggested, activity biomarkers are not perfect discriminative elements and are not always available. Adjustment of lupus treatment or initiation of a trial of empiric antibiotics should be determined based on the initial findings and patient status. Often both are required initially and tailored when a clearer scenario is at hand. An extensive assessment of a lupus cohort tested two hypotheses, demonstrating that fever is rarely associated with lupus flares in patients taking low dose of prednisone (median $10 \mathrm{mg}$ per day), with only one case presenting with fever among 73 flare episodes (Rovin et al, 2005). And also, in SLE patients with recent onset fever, moderate doses of prednisone (20 to $40 \mathrm{mg}$ /day) were related with a rapid resolution of the symptom, except in cases when infection was the cause.

Differentiation between infection and disease activity is highly important but difficult. Acute infections, systemic response to infection and disease activity share many clinical and laboratorial abnormalities. Certain biomarkers have been proposed as discriminative elements in such scenarios. C-reactive protein could be a useful tool to differentiate both conditions (Roy \& Tan, 2001), although others reports do not support this, it is our believe that the issue remains inconclusive. Procalcitonin, a precursor of calcitonin hormone is a novel marker of bacterial infection; nowadays, determination of serum level is routinely performed in hospitals as a bedside rapid measurement to provide evidence of bacterial infection, in circumstances when clinical or bacteriological diagnosis is not clear. It was suggested, that procalcitonin might be useful for distinction of infection or disease activity; however, a recent careful evaluation rejected this hypothesis; procalcitonin exerted a poor diagnostic accuracy for differentiation of both conditions, and is no longer being used with this purpose (Lanoix et al, 2011).

Systemic lupus is also reported as a cause of fever of unknown origin (FUO) in different settings, corresponding to a relevant proportion of cases with this entity being in some reports a repeated diagnosis among the inflammatory non-infectious conditions, which represent at least one third of all causes of FUO (Arce-Salinas et al, 2005).

\section{Prevention strategies}

Preventive strategies should begin with the identification and amendment of factors that predispose SLE patients to infections. This is, however easier said than done. Even though infection rates were as high as $40 \%$ prior to the widespread use of corticosteroids for the treatment of SLE, several studies have demonstrated that high dose steroids, the current angular stone of SLE treatment, increase the risk of infection. Weaker associations have been reported with the use of cyclophosphamide. Other commonly reported risk factors for infection in SLE are: high disease activity, damage accrual, nephritis and neurologic disease activity (Gladman et al, 2002; Fessler 2002). No published evidence has shown that the steroids effect over the risk of infection is independent of disease activity, and this will probably remain as it is, in view of the difficulty to dissect these two conditions. Considering this information it seems fair to admit that measures aimed at lowering disease activity should be considered the backbone of the preventive strategy against infection in SLE, even given their immunosuppressive nature.

Although inconclusive evidence suggests that certain measures of prophylaxis against infective pathogens may be in order for specific subgroups of patients based on their 
particular risks (Table 4), there are no guidelines as to which subgroups of patients may benefit the most, the agents that should be used, and the best timing to do so.

\begin{tabular}{|c|c|}
\hline $\begin{array}{l}\text { Respiratory } \\
\text { Infections }\end{array}$ & $\begin{array}{l}\text { - Influenza vaccination safe and effective (antibody response) in } \\
\text { SLE. (Abu-Shakra et al, 2007) } \\
\text { - Pneumococcal vaccine safe. Significant minority left unprotected } \\
\text { (risk factors: high disease activity and immunosuppressive use). } \\
\text { (Battafarano et al, 1998) }\end{array}$ \\
\hline Tuberculosis & $\begin{array}{l}\text { - Screening for latent TB is critical prior to high dose PDN and other } \\
\text { lupus drugs (anergy is frequent). (ATS, 2005) } \\
\text { In endemic areas prophylaxis with isoniazid may reduce the risk } \\
\text { of developing TB in patients taking > }>15 \mathrm{mg} / \text { day of PDN } \\
\text { (Hernández-Cruz B et al, 1999). }\end{array}$ \\
\hline Herpes Zoster & $\begin{array}{l}\text { - Frequency of herpes zoster is higher in patiens taking CFM than } \\
\text { other lupus drugs. Lower doses of CFM reduce risk (Houssiau F } \\
\text { et al, 2002). } \\
\text { - No data on (live attenuated) vaccine use in patients with SLE. }\end{array}$ \\
\hline B \& C Hepatitis & $\begin{array}{l}\text { - Minimal data on the course of HBV and HCV infections, antiviral } \\
\text { treatment in SLE, and effect of lupus drugs in viral replication and } \\
\text { hepatic necrosis. } \\
\text { - Increase risk of autoimmune symptoms after HBV vaccine (Geier } \\
\text { D.A. \& Geier M.R., 2005). } \\
\text { - Effect of SLE on response to HBV vaccination not clear. }\end{array}$ \\
\hline $\begin{array}{c}\text { Fungal } \\
\text { infections }\end{array}$ & $\begin{array}{l}\text { - No primary prevention is suggested for Candida, Cryptotoccus or } \\
\text { Aspergillus. } \\
\text { - Prophylaxis for pneumocystis in severe lupus mostly with lung } \\
\text { involvement is suggested (Vernovsky \& Dellaripa, 2000). No real } \\
\text { data. }\end{array}$ \\
\hline Other & $\begin{array}{l}\text { - Meningococcal vaccination recommended in asplenia but not } \\
\text { formally examined in SLE } \\
\text { - Haemophilus influenzae type B recommended in asplenia. Safe and } \\
\text { effective in SLE (antibody response). (Battafarano et al, 1998) }\end{array}$ \\
\hline
\end{tabular}

Table 4. Preventive Management of Selected Infection in SLE.

A common problem that physicians often face is whether immunization is a safe and effective strategy to prevent infections in patients with SLE or not. Concern has been raised from a group of reports that link vaccination to autoimmune manifestations. However, data from observational cohorts denotes that vaccinations are safe for the majority of SLE patients, when inactivated and component vaccines are used. For instance, a group of 70 patients with SLE received pneumococcal, tetanus and $H$. influezae type B vaccines, and none had a disease flare or any significant change in the activity status. (Battarfarano et al, 1998). The efficacy of vaccination in SLE remains elusive for the majority of vaccines. While most patients with SLE show an antibody response to vaccination, this does not imply that the patients actually gain an advantage against the pathogen. No study so far, has looked into the true protective effect (i.e.: rates of pneumonia infection) that vaccines are supposed to offer, in patients with SLE. 
The reader is encouraged to read the guidelines proposed by the British Society for Rheumatology (www.rheumatology.org.uk). Here it is recommended that live vaccines should not be used in patients taking immunosuppressive drugs or a few months after cessation of them. They also recommend that when non-live vaccines are given, an assessment of response should be sought, and to consider a booster when antibody titers are low. Finally, Barber et al proposed a set of strategies for prevention of opportunistic infections in SLE, briefly: yearly influenza vaccination, quinquenal pneumococcal vaccination, regular pap smears, TB skin test prior to starting immunosuppressive treatment and treatment with isoniazid for patients with latent TB infection. Hepatitis B, hepatitis C and HIV serology should be screened at baseline, as well as $S$. stercoralis in endemic areas (Barber et al, 2011).

\section{Final remarks}

It has been said that infections loom, like the Sword of Democles, over patients with SLE, and this is certainly not an understatement. About half of the patients with SLE will suffer a major infection in their lives and a great proportion of them will have an infection attributable death. In spite of this, only a few studies have addressed the issues that would provide clinicians with better management alternatives for infectious disease in SLE and its prevention. It is believed that SLE patients are at high risk for infections owing to intrinsic underlying immunological derangements and to the use of therapeutic regimens with immunosuppressive agents.

The use of high dose glucocorticoids, high disease activity, organ dysfunction and use other immunosuppressants, are the strongest risk factors for the development of an infection in SLE. Fever, among other findings challenges the clinician into a discriminative endeavor to establish its relation with disease activity and/or infection. Workup in such scenarios depends on a thorough physical exam. Some biomarkers have been proposed to be discriminative in this situation.

Specific measures of prophylaxis may offer benefit in patients with lupus against infection, but for the most, no controlled studies support their use. Reports of autoimmune induction with vaccination are scarce and for the majority of patients, vaccination is a safe procedure. Pneumococcal and influenza vaccinations are recommended, but no probe of true efficacy exist for these or other vaccines in patients SLE.

Many questions remain unanswered in the field of infections and SLE, among others: 1) Determining true predictors of infection in SLE such as specific immune defects, genetic markers or other biomarkers that indicates proclivity to infection. 2) Studying which specific immune derangements underlie the increase susceptibility to specific infections. 3) Evaluating which measures is likely to prevent infectious disease in SLE patients, who should receive them and what is the best timing to do so; these include studies of long-term efficacy vaccines and cost-effectiveness of their routine application in SLE. 4) Testing of proposed biomarkers that may help clinician solve a frequent diagnostic dilemma between disease activity and active infections.

\section{References}

Al-Arfaj, A.S. \& Khallil, N. (2009). Clinical and immunological manifestations in 624 SLE patients in Saudi Arabia. Lupus, Vol.18, No.5 (April), pp.465-473. 
Alzeer, A.H.; Al-Arfaj, A.; Basha, S.J. et al. (2004) Outcome of patients with systemic lupus erythematosus in intensive care unit. Lupus Vol.13, No.7 (July), pp. 537-42.

American Thoracic Society; Centers for Disease Control and Prevention; Infectious Diseases Society of America. (2005). American Thoracic Society/Centers for Disease Control and Prevention/Infectious Diseases Society of America: controlling tuberculosis in the United States. Am J Respir Crit Care Med, Vol.172, No.9 (November 1st), pp.11691227.

Arce-Salinas, C.A. \& Pérez-Silva, E. (2010). Mucormycosis complications in systemic lupus erythematosus. Lupus, Vol.19, No.1 (July), pp.985-988.

Arce-Salinas, C.A.; Morales-Velázquez, J.L.; Villaseñor-Ovies, P. \& Muro-Cruz, D. (2005) Classical fever of unknown origin (FUO): current causes in Mexico. Rev Invest Clin Vol.57, No.6 (November-December), pp.762-9.

Barber, C.; Gold, W.L. \& Fortin, P.R. (2011). Infections in the lupus patient: perspectives on prevention. Current Op Rheumatol, Vol.23, No.4 (July), pp.358-365.

Barzilai, O.; Ram, M. \& Shoenfeld, Y. (2007). Viral infection can induce the production of autoantibodies. Curr Opin Rheumatol Vol.19, No.6 (November), pp.636-643.

Battafarano, D.; Battafarano, N.; Larson, L. et al. (1998). Antigen-specific antibody responses in lupus patients following immunizations. Arthritis Rheum, Vol.41, No.10 (October), pp.1828-1834.

Becker, J. \& Winthrop K.L. (2010). Update on rheumatic manifestations of infectious diseases. Curr Opin Rheumatol Vol.22, No.1 (January), pp.72-77.

Bernatsky, S.; Boivin J.-F-; Joseph, L. et al. (2006). Mortality in systemic lupus eryhtematosus. Artthritis Rheum, Vol.58, No.8 (August), pp.2250-2257.

Borba, E.F.; Ribeiro, A.C.M.; Martin, P.; Costa, L.P.; Guedes, L.K.N. \& Bonfá, E. (2010). Incidence, risk factors, and outcome of herpes zoster in systemic lupus erythematosus. J Clin Rheumatol Vol.16, No.3 (April), pp.119-122.

Boros, P.; Muryoi, T.; Spiera, H.; Bona, C. \& Unkeless, J.C. (1993). Autoantibodies directed against different classes of $F_{C \gamma} R$ are found in sera of autoimmune patients. $J$ Immunol, Vol.150, No.5 (March), pp.2018-2024.

Bultink, I.E.; Hamann, D.; Seelen, M.A.; Hart, M.H.; Dijkmans, B.A.; Daha, M.R. \& Voskuyl, A.E. (2006). Deficiency of functional mannose-binding lectin is not associated with infections in patients with systemic lupus erythematosus. Arthritis Res Ther. Vol.8, No.6 (June), pp.R183.

Caramaschi, P.; Marocco, S.; Gobbo, M. et al. (2010). Systemic lupus erythematosus and strongyloidiasis: a multifaceted connection. Lupus Vol.19, No.7 (July), pp.872-874.

Cervera, R.; Khamashta, M.A.; Font, J. et al. (2003) Morbidity and mortality in systemic lupus erythematosus during a 10-year period. A comparison of early and late manifestations in a cohort of 1,000 patients. Medicine Vol.82, No.5 (September), pp.299-308.

Clifford, G.M.; Gallus, S.; Herrero, R. et al. (2005). Worldwide distribution of human papillomavirus types in cytologically normal women in the International Agency for research on cancer HPV prevalence surveys; a pooled analysis. Lancet Vol.366, No. 9490 (September 17-23), pp.991-998.

Cuchacovich, R. \& Gedalia, A. (2009). Pathophysiology and clinical spectrum of infections in systemic lupus erythematosus. Rheum Dis Clin North Am, Vol.35, No.1 (February), pp.75-93. 
Durán-Barragán, S.; Ruvalcaba-Naranjo, H.; Gutiérrez-Rodríguez, L. et al. (2008). Recurrent urinary tract infections and bladder dysfunction in systemic lupus erythematosus. Lupus, Vol.17, No.12 (December), pp.1117-1121.

Evans, S.J.; Watson, D.K. \& O'Sullivan, M. (2008). Reversible Hodgkin's lymphoma associated with Epstein-Barr virus occurring during azathioprine therapy for SLE. Rheumatology Vol.47, No.7 (July), pp.1103-1104.

Falagas, M.E.; Voidonikola, P.T. \& Angelousi, A.G. (2007) Tuberculosis in patients with systemic rheumatic or pulmonary diseases treated with glucocorticosteroids and the preventive role of isoniazid: A review of the available evidence. Int J Antimicrob Agents Vol.30, No.6 (December), pp.477-486.

Fessler, B. (2002). Infectious diseases in systemic lupus erythematosus: risk factors, management and prophylaxis. Best Pract Res Clin Rheumatol, Vol. 16, No.2, (April), pp.281-291.

Figueroa, J.E. \& Densen, P. (1991). Infectious diseases associated with complement deficiencies. Clin Microbiol Rev, Vol.4, No.3 (July), pp.359-95.

Fishman, D. \& Isenberg, D.A. (1997). Splenic involvement in rheumatic diseases. Semin Arthritis Rheum, Vol.27, No.3 (December), pp.141-155.

Gandhi, M.K. \& Khanna, R. (2004). Human cytomegalovirus: clinical aspects, immune regulation, and emerging treatments. Lancet Infect Dis Vol.4, No.12 (December), pp.725-738.

Geier, D.A. \& Geier, M.R. (2005). A case-control study of serious autoimmune adverse events following hepatitis B immunization. Autoimmunity. Vol.38, No.4 (June), pp.295-301.

Gladman, D.; Hussain, F.; Ibañez, D. \& Urowitz, B.M. (2002). The nature and outcome of infection in systemic lupus erythematosus. Lupus Vol.11, No.4 (April), pp.234-239.

Goldblatt, F.; Chambers, A.; Rahman, A. \& Isenberg, D.A. (2009). Infections in British patients with systemic lupus erythematosus: hospitalisations and mortality. Lupus, Vol.18, No.8 (July), pp.682-689.

Guzmán, J.; Cardiel, M.H.; Arce-Salinas, C.A.; Sánchez-Guerrero, J. \& Alarcón-Segovia, D. (1992). Measurement of disease activity in systemic lupus erythematosus. Prospective validation of 3 clinical indices. J Rheumatol Vol.19, No.10 (October), pp.1551-1558.

Hernández-Cruz, B.; Ponce-de-León-Rosales, S.; Sifuentes-Osornio, J.; Ponce-de-LeónGarduño, A. \& Díaz-Jouanen, E. (1999). Tuberculosis prophylaxis in patients with steroid treatment and systemic rheumatic diseases. A case-control study. Clin Exp Rheumatol, Vol.17, No.1 (January-February), pp.81-87.

Houssiau, F.; Vasconcelos, C.; D'Cruz, D. et al. (2002). Immunospuressive therapy in lupus nephritis: the Euro-Lupus Nehritis Trial, a randomized trial of low-dose versus high-dose intravenous cyclophosphamide. Arthritis Rheum, Vol.46, No.8 (August), pp.2121-2131.

Iliopoulos, A.G. \& Tsokos, G.C. (1996). Immunopathogenesis and spectrum of infections in systemic lupus erythematosus. Semin Arthritis Rheum Vol.25, No.5 (April), pp.318336.

Jakobsen, P.H.; Morris-Jones, S.D.; Hviid, L. et al. (1993). Anti-phospholipid antibodies in patients with Plasmodium falciparum malaria. Immunology Vol.79, No.4 (August), pp.653-657. 
Kang, I. \& Park, S.H. (2003). Infectious complications in SLE after immunosuppressive therapies. Curr Opin Rheumatol, Vol.15, No.5 (September), pp.528-534.

Kang, I.; Quan, T.; Nolasco, H. et al. (2004) Defective control of latent Epstein-Barr virus infection in systemic lupus erythematosus. J Immunol Vol.172, No.2 (January), pp.1287-1294.

Kang, T.Y.; Lee, H.S.; Kim, T.H.; Jun, J.B. \& Yoo, D.H. (2005). Clinical and genetic risk factors of herpes zoster in patients with systemic lupus erythematosus. Rheumatol Int, Vol.25, No.2 (March), pp.97-102.

Karim MY. (2006). Immunodeficiency in the lupus clinic. Lupus, Vol.15, No.3 (March), pp.127-131.

Kasitanon, N.; Louthrenoo, W.; Sukitawut, W. \& Vichainun, R. (2002). Causes of death and prognostic factors in Thai patients with systemic lupus erythematosus. Asian Pac J Allergy Immunol, Vol.20, No.2 (June), pp.85-91.

Klemperer, P.; Pollack, A. \& Baehr, G. (1941). Pathology of disseminated lupus erythematosus. Arch Pathol, Vol.32 (July), pp.569-631.

Klumb, E.M.; Pinto, A.C.; Jesus, G.R. et al. (2010). Are women with lupus at higher risk of HPV infection? Lupus Vol.19, No.13 (November), pp.1485-1491.

Kraus, A.; Cabral, A.R.; Sifuentes-Osornio, J. \& Alarcón-Segovia, D. (1994). Listeriosis in patients with connective tissue diseases. J Rheumatol, Vol.21: No.4, (April), pp.635638.

Lanoix, J.P.; Bourgeois, A.M.; Schmidt, J. et al. (2011). Serum procalcitonin does not differentiate between infection and disease flare in patients with systemic lupus erythematosus. Lupus, Vol.20, No.2 (February), pp.125-130.

Lee, S.S.; Lawton, J.W.; Chan, C.E.; Li, C.S.; Kwan, T.H. \& Chau, K.F. (1992). Antilactoferrin antibody in systemic lupus erythematosus. Br J Rheumatol, Vol.31, No.10 (October), pp.669-673.

Leone, F.C.; Campos, L.M.A.; Febrônio, M.V.; Marques, H.H.S. \& Silva, C.A. (2007). Risk factors associated with the death of patients hospitalized for juvenile systemic lupus erythematosus. Br J Med Biol Res, Vol.40, No.7 (July), pp.903-1002.

Mathers ,C.D. \& Loncar, D. (2006). Projections of global mortality and burden of disease from 2002 to 2030. PLoS Med, Vol.3, No.11 (November), pp.e442.

Mok, C.C.; Yuen, K.Y. \& Lau, C.S. (1997). Nocardiosis in systemic lupus erythematosus. Semin Arthritis Rheum, Vol.26, No.4 (February), pp.675-863.

Mok, C.C.; Lee, K.W.; Ho, C.T.K.; lau, C.S. \& Wong, R.W.S. (2000). A prospective study of survival and prognostic indicators in systemic lupus erythematosus i a southern Chinese population. Rheumatology, Vol.39. No.4 (April), pp.399-406.

Mok, M.Y.; Ip, W.K.; Lau, C.S.; Lo, Y; Wong, W.H., \& Lau, Y.L. (2007). Mannose-binding lectin and susceptibility to infection in Chinese patients with systemic lupus erythematosus. J Rheumatol, Vol.34, No.6 (June) pp.1270-1276.

Mok, M.Y.; Wong, S.S.; Chan, T.M.; Fong, D.Y.; Wong, W.S. \& Lau, C.S. (2007). Nontuberculous mycobacterial infection in patients with systemic lupus erythematosus. Rheumatology Vol.46, No.2 (February), pp.280-284.

Monticielo, O.A.; Mucenic, T.; Xavier, R.M.; Brenol, J.C. \& Chies, J.A. (2008). The role of mannose-binding lectin in systemic lupus erythematosus. Clin Rheumatol, Vol.27, No.4 (April), pp.413-419. 
Navarro-Zarza, J.E.; Álvarez-Hernández, E.; Casasola-Vargas, J.C. et al. (2010). Prevalence of community-acquired and nosocomial infections in hospitalized patients with systemic lupus erythematosus. Lupus, Vol.19, No.1 (January), pp.43-48.

Nossent, J.; Cikes, N.; Kiss, E. et al. (2007). Current causes of death in systemic lupus erythematosus in Europe, 2000-2004: relation to disease activity and damage accrual. Lupus, Vol.16, No.5 (May), pp.309-317.

Oh., H.M.; Chng, H.H.; Boey, M.L. \& Feng, P.H. (1993). Infections in systemic lupus erythematosus. Singapore Med J, Vol. 34, No.5 (October), pp.406-408.

Petri, M. Infection in systemic lupus erythematosus. (2008). Rheum Dis Clin North Am, Vol.24, No.2 (May), pp.423-456.

Pickering, M.C.; Botto, M.; Taylor, P.R.; Lachmann, P.J. \& Walport, M.J. (2000). Systemic lupus erythematosus, complement deficiency, and apoptosis. Adv Immunol. Vol.76, pp.227-324.

Pons-Estel. B.; Catoggio, L.J.; Cardiel, M.H. et al. (2004). The GLADEL multinational Latin American prospective inception cohort of 1,214 patients with systemic lupus erythematosus. Ethnic and disease heterogeneity among "hispanics". Medicine. Vol. 83, No.1 (January), pp.1-17.

Prabu, V. \& Agrawal, S. (2010). Systemic lupus eryhtematosus and tuberculosis: A review of complex interactions of complicated diseases. J Postgrad Med. Vol.56, No.3 (JulySeptember), pp.244-250.

Ramírez-Gómez, L.A.; Velásquez, J.F.; Granda, P.; Alfonzo-Builes, C. \& Jaimes, F. (2007). Association between disease activity and risk of nosocomial infection in patients from a University Hospital at Medellín: prospective study 2001-2004. Rev Col Reumatol, Vol.24, No.3 (September), pp.177-186.

Ramos-Casals, M.; Font, J.; García-Carrasco, M.; Cervera, R. et al. (2000) Hepatitis C virus infection mimicking systemic lupus erythematosus: study of hepatitis $C$ virus infection in a series of 134 Spanish patients with systemic lupus erythematosus. Arthritis Rheum, Vol.43, No.12 (Decemeber), pp.2801-2806.

Ramos-Casals, M.; Cuadrado, M.J.; Alba, P. et al. (2008). Acute viral infections in patients with systemic lupus erythematosus: description of 23 cases and review of the literature. Medicine. Vol.87, No.6 (Novemeber), pp.311-318.

Rovin, B.H.; Tang, Y.; Sun, J. et al. (2005). Clinical significance of fever in the systemic lupus erythematosus patient receiving steroid therapy. Kidney Int, Vol.68, No.2 (August), pp.747-759.

Roy, S. \& Tan K.T. (2001). Pyrexia and normal C-reactive protein (CRP) in patients with systemic lupus erythematosus: always consider the possibility of infection in febrile patients with systemic lupus erythematosus regardless of CRP levels. Rheumatology, Vol.40, No.3 (March), pp.349-350.

Rubin, L.A.; Urowitz, M.B. \& Gladman, D.D. (1985). Mortality in systemic lupus erythematosus: the bimodal pattern revisited. Q J Med, Vol.55, No.216 (April), pp.87-98.

Ruiz-Irastorza, G.; Olivares, N.; Ruiz-Arruza, I.; Martínez-Berriotxoa, A.; Egurbide, M.V. \& Aguirre, C. (2009) Predictors of major infections in systemic lupus eryhtematosus. Arthritis Res Ther, Vol.4, No.11, pp.R109. 
Schnabel, A.; Csernok, E.; Isenberg, D.A.; Mrowka, C. \& Gross, W.L. (1995). Antineutrophil cytoplasmic antibodies in systemic lupus erythematosus. Prevalence, specificities, and clinical significance. Arthritis Rheum, Vol.38, No.5 (May), pp.633-637.

Sebastiani, G.D. \& Galeazzi, M. (2009). Infection-genetics relationship in systemic lupus erythematosus. Lupus, Vol.18, No.13 (November), pp.1169-1175.

Seta, N.; Shimizu, T.; Nawata, M. et al. (2002) A possible novel mechanism of opportunistic infection in systemic lupus erythematosus, based on a case of toxoplasmic encephalopathy. Rheumatology, Vol.41, No.9 (September), pp.1072-1073.

Severin, M.C.; Levy, Y. \& Shoenfeld, Y. (2003). Systemic lupus erythematosus and parvovirus B19. Casual coincidence or causative culprit? Clin Rev Allergy Immunol, Vol.25, No.1 (August), pp.41-8.

Sharlala, H. \& Adebajo, A. (2008). Virus-induced vasculitis. Curr Rheumatol Rep, Vol.10, No.6 (December), pp.449-452.

Shepard, C.W.; Finelli, L. \& Alter, M.J. (2005), Global epidemiology of hepatitis C virus infection. Lancet Infect Dis, Vol.5, No.9 (September), pp.558-567.

Shyam, C. \& Malaviya, A.N. (1996) Infection-related morbidity in systemic lupus erythematosus: a clinical-epidemiological study from northern India. Rheumatol Int, Vol.16, No.1, pp.1-3.

Singh, S.; Chatterjee, S.; Sohoni, R.; Badakere, S. \& Sharma, S. (2001). Sera from lupus patients inhibit growth of P. falciparum in culture. Autoimmunity, Vol.33, No.4, pp.253-263.

Super, M.; Thiel, S.; Lu, J.; Levinsky, R.J. \& Turner, M.W. (1989). Association of low levels of mannan-binding protein with a common defect of opsonisation. Lancet, Vol.2, No.8674 (Novemeber 25th), pp.1236-1239.

Uramoto, K.M.; Michet, C.J.; Thumboo, J. et al. (1999). Trends in the incidence and mortality of systemic lupus erythematosus, 1950-1992. Arthritis Rheum, Vol.42, No.1 (January), pp.46-50.

Vernovsky, I. \& Dellaripa, P.F. (2000). Pneumocystis carinii pneumonia prophylaxis in patients with rheumatic diseases undergoing immunosuppressive therapy: prealence and associated features. J Clin Rheumatol, Vol.6, No.2, (April), pp.94-101.

Wadee, S.; Tikly, M. \& Hopley, M. (2007). Causes and predictors of death in South Africans with systemic lupus erythematosus. Rheumatology, Vol.46, No.9 (September), pp.1487-1491.

Yang, C.D.; Wang, X.D.; Ye, S. et al. (2007). Clinical features, prognostic and risk factors of central nervous system infections in patients with systemic lupus erythematosus. Clin Rheumatol, Vol.26, No.6 (June), pp.895-901.

Yong, P.F.; Aslam, L.; Karim, M.Y. \& Khamashta, M.A. (2008). Management of hypogammaglobulinaemia occurring in patients with systemic lupus erythematosus. Rheumatology, Vol.47, No.9 (September), pp.1400-14005.

Yu, C.L.; Chang, K.L.; Chiu, C.C. et al. (1989). Defective phagocytosis, decreased tumour necrosis factor-alpha production, and lymphocyte hyporesponsiveness predispose patients with systemic lupus erythematosus to infections. Scand J Rheumatol, Vol.18, No.2 (February), pp.97-105.

Yun, J.E.; Lee, S.W.; Kim, T.H. et al. (2002). The incidence and clinical characteristics of Mycobacterium tuberculosis infection among systemic lupus erythematosus and 
rheumatoid arthritis patients. Clin Exp Rheumatol, Vol.20, No.2 (March-April), pp.127-132.

Zandman-Goddard, G. \& Shoenfeld, Y. (2003). SLE and infections. Clin Rev Allergy Immunol, Vol.25, No.1 (August), pp.29-39.

Zanini, G.M.; De Moura Carvalho, L.J.; Brahimi, K. et al. (2009). Sera of patients with systemic lupus erythematosus react with plasmodial antigens and can inhibit the in vitro growth of Plasmodium falciparum. Autoimmunity, Vol.42, No.6 (September), pp.545-552.

Zonana-Nacach, A.; Camargo-Coronel, A.; Yañez, P.; Sánchez. L.; Jiménez-Balderas, F.J. \& Fraga, A. (2001). Infections in outpatients with systemic lupus erythematosus: a prospective study. Lupus, Vol.10, No.7 (July), pp.505-510. 


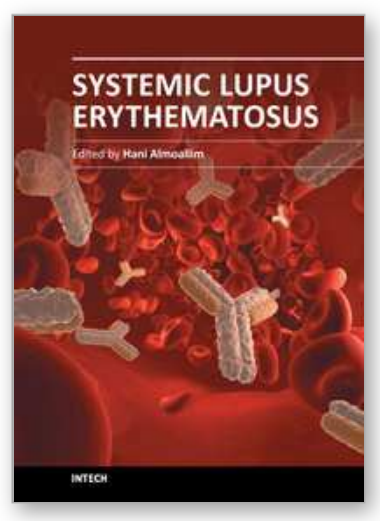

\author{
Systemic Lupus Erythematosus \\ Edited by Dr Hani Almoallim
}

ISBN 978-953-51-0266-3

Hard cover, 554 pages

Publisher InTech

Published online 21, March, 2012

Published in print edition March, 2012

This book provides a comprehensive overview of the basic and clinical sciences of Systemic Lupus Erythematosus. It is suitable for basic scientists looking for detailed coverage of their areas of interest. It describes how advances in molecular biology have increased our understanding of this disease. It is a valuable clinical resource for practicing clinicians from different disciplines including rheumatologists, rheumatology fellows and residents. This book provides convenient access to information you need about cytokines, genetics, Fas pathway, toll like receptors and atherogenesis in SLE. Animal models have been reviewed as well. How to avoid delay in SLE diagnosis and management, in addition to various clinical manifestations including pregnancy and SLE have all been explained thoroughly in this book.

\title{
How to reference
}

In order to correctly reference this scholarly work, feel free to copy and paste the following:

C. Alejandro Arce-Salinas and Pablo Villaseñor-Ovies (2012). Infections and Systemic Lupus Erythematosus, Systemic Lupus Erythematosus, Dr Hani Almoallim (Ed.), ISBN: 978-953-51-0266-3, InTech, Available from: http://www.intechopen.com/books/systemic-lupus-erythematosus/infectious-in-systemic-lupus

\section{INTECH}

open science | open minds

\section{InTech Europe}

University Campus STeP Ri Slavka Krautzeka 83/A 51000 Rijeka, Croatia Phone: +385 (51) 770447

Fax: +385 (51) 686166 www.intechopen.com

\section{InTech China}

Unit 405, Office Block, Hotel Equatorial Shanghai No.65, Yan An Road (West), Shanghai, 200040, China 中国上海市延安西路65号上海国际贵都大饭店办公楼405单元 Phone: +86-21-62489820

Fax: $+86-21-62489821$ 
(C) 2012 The Author(s). Licensee IntechOpen. This is an open access article distributed under the terms of the Creative Commons Attribution 3.0 License, which permits unrestricted use, distribution, and reproduction in any medium, provided the original work is properly cited. 